\title{
Cleft lip and palate in the Oxford Area An examination of the evidence for clustering in space and time
}

\author{
A. B. HEATH
}

From the Department of Medical Statistics, University of Newcastle upon Tyne

SUMmARY Children with cleft lip and/or palate born during the period 1965-74 inclusive in the Oxford area were examined for evidence of any tendency for clustering. The methods suggested by Knox (1963), David and Barton (1966), and Smith and Pike (1974) were used. No clustering was evident in space or in time. There was some indication of clustering in space-time for isolated cleft palate during the period 1965-71, but this was not repeated during 1972-74.

When studying a disease for evidence of clustering, there are three types of possible clustering that must be investigated. These are:

1. Clustering in space

2. Clustering in time

3. Interaction between space and time concentrations.

The last of these, (3), amounts to the question: Are cases which occur close in space also close in time? The presence of clustering usually indicates some causal environmental factor, which is local in both time and space, such as an infection.

The possibility of these forms of clustering affecting the incidence of cleft lip and palate in the Oxford area, for the years 1965-74 inclusive, is investigated.

\section{The data}

The data consist of the date of birth and the mother's home address for each case of a cleft lip and/or palate in a child born during the period 1965-74 in the Oxford Regional Hospital Board area. This information was obtained from the Oxford Record Linkage Study. The map references of the addresses were obtained from 6 inch : 1 mile Ordnance Survey maps. For villages and small towns where the exact address could not be pinpointed the map reference was taken at some central point. Most references are accurate to within less than $1 \mathrm{~km}$. A few cases could not be traced and were omitted from the study.

\section{SPACE-TIME CLUSTERING}

Knox $(1963,1964)$ devised a test for the interaction of space and time clustering, and discussed the problems of detecting any clustering when the incidence of the disease was relatively rare. In the test the pairs of births were counted to see how many were close in both space and time. By close we mean within some previously specified critical time or distance.

The data for 1965 to 1971 were originally used, and the test of Knox (1963) was performed. An exact formula for the variance of Knox's test statistics, obtained by David and Barton (1966), was used. When the 1972-74 data became available the test was repeated on the new data independently, and then on the combined data set.

It has been suggested that isolated cleft palate is aetiologically different from cleft lip, which may or may not have an associated cleft palate (Fraser, 1970). For this reason, the Knox test was carried out on cases of isolated cleft palate, and the cases of cleft lip with or without cleft palate, separately.

Various different critical times and distances were used for specifying whether a pair were 'close'. The results are shown in Tables 1, 2, and 3. The figures show the number of pairs close in space and time, together with the expected values

Table 1 Results of Knox's tests for 1965-71 inclusive

\begin{tabular}{|c|c|c|c|c|c|c|c|}
\hline \multirow{4}{*}{$\begin{array}{l}\text { Alternative } \\
\text { critical } \\
\text { distance } \\
(\mathrm{km})\end{array}$} & & \multicolumn{6}{|c|}{ Alternative critical time (months) } \\
\hline & \multicolumn{3}{|c|}{1} & \multicolumn{2}{|l|}{2} & \multicolumn{2}{|l|}{3} \\
\hline & 2 & $\begin{array}{r}2 \\
14\end{array}$ & $\begin{array}{l}(0 \cdot 80) \\
(8 \cdot 25)^{*}\end{array}$ & $\begin{array}{r}5 \\
23\end{array}$ & $\begin{array}{l}(1.59)^{*} \\
(16.98)\end{array}$ & $\begin{array}{r}7 \\
27\end{array}$ & $\begin{array}{l}(2 \cdot 38)^{*} \\
(25 \cdot 57)\end{array}$ \\
\hline & 3 & 22 & $\begin{array}{l}(1 \cdot 81) \\
(15 \cdot 14)^{*}\end{array}$ & $\begin{array}{r}5 \\
39\end{array}$ & $\begin{array}{r}(3 \cdot 58) \\
(31 \cdot 16)\end{array}$ & 10 & $(5 \cdot 34)^{*}$ \\
\hline
\end{tabular}

Upper figures relate to isolated cases of cleft palate

Lower figures relate to all cases of cleft lip and/or palate

* Represents a significant result at the $5 \%$ level

Total number of cases:

Isolated cleft palate 64

All cases

171 
Table 2 Results of Knox's tests for 1972-74 inclusive

\begin{tabular}{|c|c|c|c|c|c|}
\hline \multirow{4}{*}{$\begin{array}{l}\text { Alternative } \\
\text { critical } \\
\text { distance } \\
\text { (km) }\end{array}$} & \multicolumn{5}{|c|}{ Alternative critical time (months) } \\
\hline & \multicolumn{2}{|r|}{1} & 2 & \multicolumn{2}{|l|}{3} \\
\hline & 20 & $\begin{array}{ll}0 & (0 \cdot 62) \\
0 & (2 \cdot 37)\end{array}$ & $\begin{array}{ll}1 & (1 \cdot 21) \\
4 & (4 \cdot 75)\end{array}$ & $\begin{array}{l}2 \\
6\end{array}$ & $\begin{array}{l}(1 \cdot 62) \\
(7 \cdot 05)\end{array}$ \\
\hline & 31 & $\begin{array}{ll}1 & (1 \cdot 23) \\
2 & (4 \cdot 30)\end{array}$ & $\begin{array}{ll}3 & (2.41) \\
8 & (8.61)\end{array}$ & $\begin{array}{r}4 \\
10\end{array}$ & $\begin{array}{l}(3 \cdot 25) \\
(12 \cdot 79)\end{array}$ \\
\hline
\end{tabular}

Table 3 Results of Knox's tests for 1965-74 inclusive

\begin{tabular}{|c|c|c|c|c|}
\hline \multirow{4}{*}{$\begin{array}{l}\text { Alternative } \\
\text { critical } \\
\text { distance } \\
(\mathrm{km})\end{array}$} & \multicolumn{4}{|c|}{ Alternative critical time (months) } \\
\hline & \multicolumn{2}{|l|}{1} & 2 & 3 \\
\hline & 21 & $\overline{15} \quad(10 \cdot 57)$ & $\begin{array}{rr}6 & (2 \cdot 76) \\
28 & (21 \cdot 77)\end{array}$ & $\begin{aligned} 9 & (3.977 *) \\
34 & (32.61)\end{aligned}$ \\
\hline & $3 \frac{1}{2}$ & $\overline{25}(18 \cdot 83)$ & $\begin{array}{rr}8 & (5 \cdot 20) \\
49 & (38 \cdot 79)\end{array}$ & $\begin{array}{ll}14 & (7 \cdot 50)^{*} \\
64 & (58 \cdot 12)\end{array}$ \\
\hline
\end{tabular}

in brackets. None of the tests done on the cases of cleft lip separately showed any significant clustering. A few tests were also carried out with values of critical time and distance outside the range shown, but the results did not prove significant.

Knox (1964) pointed out that a high space-time concentration could be the result of a movement of space clusters in time. If there were a population migration during the period of study, there is a possibility that this would lead to a significant result, and spurious clustering would be detected. When the original work on the 1965-71 data was carried out, it was decided to subject a control series to the same analysis as the cases, to counter this possibility. Any migratory trends would result in a high value of pairs of controls close in both time and space.

The controls were matched for mother's age, parity, and social class, as it was thought that these factors would influence the tendency of people to move. The controls were obtained from an unmatched sample of 1000 normal births, taken from the records of the Oxford Record Linkage Study. Matched controls could not be found for a few of the cases.

The results for the controls were all nonsignificant. It did not appear that population migration was causing any spurious results, and no further tests were carried out using the controls for space-time clustering.

SPACE CLUSTERING

Clearly all births will occur in space clusters as the population lives in clusters, towns forming areas of high concentrations of births, and rural areas forming areas of low concentration. To detect any clustering of the cleft cases, which is high in relation to this, it is necessary to compare the cases with a series of control births.

One method of doing this is outlined by Smith and Pike (1974). Suppose we have $N$ cases of clefts. If we select a control birth for each case, we obtain $\mathbf{N}$ pairs. To test for any clustering we use a randomisation test.

If, for each pair, one birth is selected at random, a series of $N$ births result. If we define $Z$ as the number of pairs of these births which are close in space, then $\mathrm{Z}$ will have a distribution which could, in theory, be evaluated by considering each of the $2^{n}$ ways of selecting $\mathrm{N}$ births from the $\mathrm{N}$ pairs.

If we consider $Z^{*}$, the number of pairs of cases close in space, as one realisation of $Z$, from the distribution described above, a significantly high result will be evidence that cases of clefts occur in space clusters, compared with the controls.

Lloyd and Roberts (1973) noted that spurious spatial clustering may be detected if the disease shows a relationship with, say, social class. In this case clustering might merely indicate the tendency of persons in the same social class to live in the samearea. For this reason, the controls used previously for the Knox test, which had been matched for $\overrightarrow{0}$ social class, parity and mother's age, were used.

The work was first carried out on the data for 1965-71, using the cases for which matched controls were available. This resulted in a series of 155 pairs of cases and controls. To obtain estimates of the mean and variance of the distribution of $Z$, the distribution was simulated, by taking 300 random realisations of $Z$. The number of close pairs of cases was also calculated. A distance of $5 \mathrm{~km}$ (3.14 miles) was suggested by the Oxford Record Linkage Study as the initial distance and this is the figure used. The results were as follows:

$\begin{array}{ll}\text { Number of close pairs of cases: } & 1039 \\ \text { Estimated mean of } Z: & 1050 \text { with } S E \\ & 6.03 \\ \text { Estimated variance of } Z: & 12102 \text { with } \\ & \text { SE } 939\end{array}$

There is thus no evidence of cases of clefts occurring in space clusters.

EQUIVALENCE TO KNOX'S TEST

Smith and Pike (1974) showed how the use of unmatched controls could be regarded as a special case of the Knox test. Although the controls we used were matched, the technique was used to compare the results obtained by simulation with those

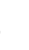


calculated from the Knox test. The resulting values were:

$$
\begin{array}{lll}
\text { Mean } & = & 1049 \\
\text { Variance } & = & 11756
\end{array}
$$

The estimated mean and variance from the simulation are thus well within sampling error of the calculated mean and variance. This would seem to indicate that the matching did not have any effect.

\section{TIME CLUSTERING}

In an exactly analogous way, the Knox test can be adapted to provide a test for clustering in time alone.

This was done for all cases of clefts, from 1965 to 1974, using a critical time of two months. The results are as follows:

$\begin{array}{lll}\text { Pairs of cases close in time } & =731 \\ \text { Expectation } & 731 \\ \text { Variance } & =504\end{array}$

There is, therefore, no evidence of any tendency for cases to occur in time clusters when compared with the controls.

\section{Discussion}

In a recent study of 194 infants with clefts of the lip and/or palate in Finland (Saxén, 1975), significant associations were found with maternal febrile illness, including influenza, during the first trimester. It would seem likely that if an infection were important in the genesis of these malformations, clustering would be found in time, and also space-time.

The tests for clustering in space and for clustering in time, gave no indication of any tendency for the cases of cleft lip and/or palate to occur in clusters.

The tests for space-time clustering, when originally applied to the data for 1965-71, gave a few significant results particularly for isolated cleft palate. There were no significant results for cleft lip treated separately. The fact that several different combinations of critical times and distances were used, however, makes the interpretation of these difficult. We are, in effect, looking for the times and distances which give the biggest difference between observed and expected values. There is a possibility that the results are spurious, resulting from the large number of tests carried out. The data for 1972-74 give no confirmation of a tendency for isolated cleft palate to occur in clusters.

A possible explanation for the significant results in 1965-71 not being repeated in 1972-74 is that a specific infection present during the first period of study, which affected the genesis of the malformation, was not present in the second. Another possibility is that with the smaller amount of data for the second period, the power of the test to detect a slight effect was decreased.

I should like to thank the Director of the Oxford Record Linkage Study, Dr J. A. Baldwin, for permission to use the data.

I am grateful to Mrs Jean Fedrick of the Oxford Record Linkage Study for supplying the data, and for her help during the preparation of this paper. I am also grateful to Dr J. F. Bithell, of the Oxford University Department of Biomathematics, for his help and advice.

Reprints from A. B. Heath, Department of Medical Statistics, The University, 21 Claremont Place, Newcastle upon Tyne NE2 4AA.

\section{References}

David, F. N., and Barton, D. E. (1966). Two space-time interaction tests for epidemicity. British Journal of Preventive and Social Medicine, 20, 44-48.

Fraser, F. C. (1970). The genetics of cleft lip and cleft palate. American Journal of Human Genetics, 22, 336-352.

Knox, G. (1963). Detection of low intensity epidemicity: Application to cleft lip and palate. British Journal of Preventive and Social Medicine, 17, 121-127.

Knox, G. (1964). Epidemiology of childhood leukaemia in Northumberland and Durham. British Journal of Preventive and Social Medicine, 8, 17-24.

Lloyd, S., and Roberts, C. J. (1973). A test for space clustering and its application to congenital limb defects in Cardiff. British Journal of Preventive and Social Medicine, 27, 188-191.

Saxén, I. (1975). Epidemiology of cleft lip and palate. British Journal of Preventive and Social Medicine, 29, 103-110.

Smith, P. G., and Pike, M. C. (1974). A note on a 'close pairs' test for space clustering. British Journal of Preventive and Social Medicine, 28, 63-64. 